\title{
Optimized Distribution of Beijing Population Based on CA-MAS
}

\author{
Haoguang Liang ${ }^{1}$ and Zhong Wang ${ }^{2}$ \\ ${ }^{1}$ Beijing International Studies University, Beijing 100101, China \\ ${ }^{2}$ Beijing Academy of Social Sciences, Beijing 100101, China \\ Correspondence should be addressed to Zhong Wang; wangxyz@tsinghua.org.cn
}

Received 2 November 2016; Accepted 15 February 2017; Published 12 March 2017

Academic Editor: Paolo Renna

Copyright (c) 2017 Haoguang Liang and Zhong Wang. This is an open access article distributed under the Creative Commons Attribution License, which permits unrestricted use, distribution, and reproduction in any medium, provided the original work is properly cited.

\begin{abstract}
In recent years rapid expansion of populations, disruption of ecological environments, and power shortages to areas of high population density in undeveloped areas have appeared in major cities in China. Well-planned population distribution in a city has become one of the key development strategies of urbanization in the country. Taking Beijing as a case-study and using 2010 as the base period, this study simulates city population size and distribution during 2011-2030 using the CA-MAS model. The results showed that (1) the unplanned layout of Beijing's population is inefficient and will result in the slow agglomeration of populations into surrounding small towns, (2) the suburbanization of the population (while employment opportunities remain centralized) increases the stress of the city commuters, (3) the current policy guiding the distribution of residential and commercial areas is effective, accelerating the formation of small town clusters, which play a role in the city's radiation and diffusion, contributing to reducing urban commuter stress, and (4) promoting the homogenization of public resources, planning the development of a multicenter urban area, and promoting mixed use (commercial and residential) zoning are the main measures recommended to strengthen the sustainability of Beijing's urban development and to optimize spatial layout.
\end{abstract}

\section{Introduction}

China's urbanization is not only a strategic focus during this stage of its development, but is also an inexorable trend. The rate of China's urbanization is roughly the same as the United States had one hundred years ago: the stage of rapid urbanization. During the process of urbanization, the spatial distribution of the population strongly influences the quality of urbanization. The spatial distribution of urban population is closely related to the economy, the degree of urbanization, and employment, amongst other factors that influence quality of life [1]. Studying the optimized distribution of the urban population has theoretical importance and practical significance. Understanding it can promote the coordinated development of population, resources, and environment and promote urban ecological security, which is essential for achieving sustainable development [2]. In Beijing the population is currently distributed in an irrational and unoptimized manner. As the capital of China, optimized distribution of population in Beijing could provide an important reference for other cities.
Social complex adaptive system modeling and simulation technology have been continuing to mature and be widely used, and this has helped research into the spatial distribution of urban populations make great progress towards optimizing cities with large-scale, multilevel, and multiagent economies, like Beijing. CA-MAS is a theoretical model developed and formed by fusing the Cellular Automaton and Multiagent System for Models, and it has been widely used in many fields [3]. The CA-MAS model can be used to simulate and explain how the commuting and employment impact the distribution of productive forces in the process of urbanization.

International literature on this topic has given attention to topics such as urban population distribution forecasting [4], urban population mobility [5] and its influencing factors [6], impacts of employment on the population distribution [710], and bearing capacity of an urban population [7]. Research methods in this field have gradually developed from CA simulation into CA-MAS simulation. Cellular automata (CA) and multiagent system (MAS) are two unique approaches of complex systems [11]. Sirakoulis et al. [12] used CA theory 
and methods to quantify environmental factors (taking distributed geographic location data as samples) and to construct a prediction model of population growth and residence changes [4]. Guan et al. [5] used the neural network to adjust CA parameters and were thus able to more closely approach the real situation of population development with regard to geographical location and local environments in Beijing [5]. Based on CA and GIS, Clarke and Gaydos [6] predicted the long-term development of Washington and San Francisco and were able to create a simulation of the population mobility between the two cities [6]. In recent years, MAS has been introduced into CA simulation models by international scholars to study the urban population distribution forecast [7-10] and optimization [13-15]. Chinese research has been behind this international benchmark, and relevant Chinese literature has focused on problems such as spatial structure and concentration rules for urban populations [16-18], urban population suburbanization [19], carrying capacity of urban population [20, 21], and population employment release $[17,18]$. With regard to research methods, Chinese scholars have begun to attach importance to the simulation model, and some scholars have made simulations to predict the population distribution of Beijing $[17,18,22]$ and Yangtze River Delta $[2,19,23]$.

Overall regarding research content, there has been a greater focus on studies of urban population distribution prediction than on studies of the optimization of distribution. Regarding research methods, the CA-MAS method has been applied in many fields, but relatively infrequently put to use to study optimized distribution of urban population. Therefore, this paper addresses an important research shortfall, as it takes Beijing as an example, and aims to provide policy recommendations for the management of urban populations in Beijing. This also provides a reference for other Chinese cities in population control.

\section{Research Areas and Methods}

2.1. Research Areas. Beijing is a center of politics, culture, economy, financial management, technology, education, transportation, tourism, and international exchanges of China. Its population can be expected to continue growing over the longer term. Since 2005, the resident population of Beijing has been continuously and rapidly growing: from 15,380,000 in 2005 to 21,710,000 in 2015, as shown in Figure 1. This rapid population growth has promoted both economic growth and social development, and at the same has created a large demand for housing, transportation, education, and health care. This in turn has been accompanied by the resource consumption necessary to meet these demands, such as land development, housing construction, and energy and water consumption [24]. At present, both the demand for resources and the vulnerability of the environment continue to increase in Beijing. This makes the conflicts between the rapid expansion of urbanization and the carrying capacity of local resources and the environment increasingly prominent. While this is partly due to the rapid expansion of the population, a more important factor has been the poor organization of population distribution. When calculated using either the

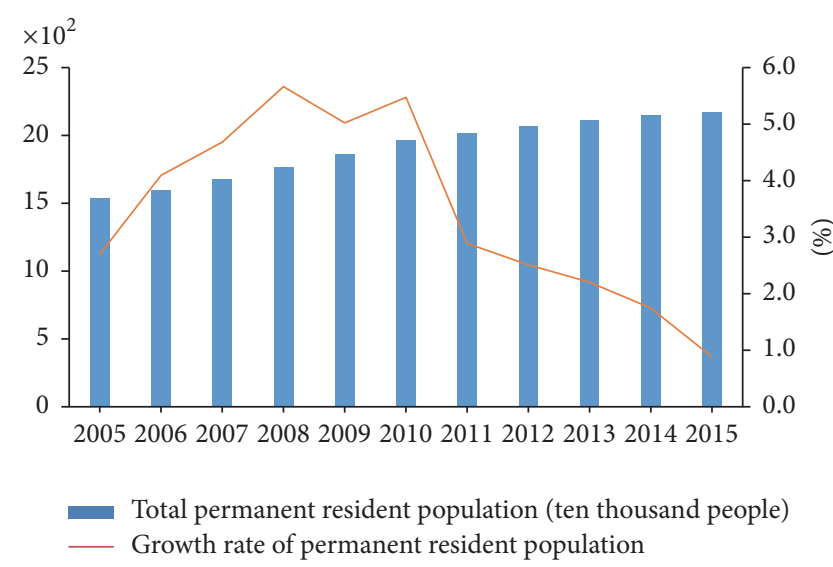

FIgURE 1: Map of Beijing population from 2005 to 2015.

theory of urban capacity or the practical experience of other international metropolises, the existing population in Beijing is still within the carrying range. Rational distribution of the population is essential to Beijing for it to successfully become a World City and to achieve sustainable development. Additionally, it is necessary to illustrate that the population change studied in this paper is limited to the 16 local counties in Beijing.

2.2. Research Methods. The construction of this model includes three steps: (1) CA design, (2) MAS design, and (3) Integration of models. CA design (1) is focused on constructing a model of the geospatial environment of the population distribution. The whole environment of the designed model is made of seven cellular CA. MAS design (2) is focused on constructing a model for multiagents and their behaviors. Integration of models (3) is done to construct a model for geospatial environmental changes caused by the agents' behaviors [25].

2.2.1. CA Design. The migration behaviors of the residents are affected by environmental factors but will also lead to the "trend or field" of changes in geographical environmental factors. Thus it is necessary to extract the relevant dominant factor of each environmental factor as the basis of quantization $[26,27]$. The state parameters of environmental factors will be the quantitative indicators regarding "power or field" as per capita relative density. In the current situation in Beijing, there are seven major environmental factors, which are displayed as seven layers of cellular automata. These include income per capita, green space per capita, consumption per capita, and residential density as the dominant factors and industrialization, urbanization, and suburbanization of residence as the main driving forces. These are depicted in Table 1.

These seven factors construct the environment surrounding the agents. Governmental policy and planning can change the parameter "environmental state," and the dynamic migration of residents has a continued effect on the environmental state parameters in each cellular automaton section, which in turn affects population density. 
TABLE 1: Composition of seven layers of cellular automata.

\begin{tabular}{llll}
\hline Environmental factor & State parameter & Dominant factor & Driving force \\
\hline Average room rate & $\mathrm{CNY} / \mathrm{m}^{2}$ & Per capita income & Suburbanization \\
Natural environment & Green area & Green space per capita & Suburbanization \\
Commercial service & Production value of tertiary industry & Consumption per capita & Urbanization \\
Traffic convenience & Working hours & Residential density & Urbanization \\
Humanistic education & School per capita & Residential density & Urbanization \\
Medical treatment and public health & Organization $/ \mathrm{km}^{2}$ & Residential density & Urbanization \\
Employment environment & Employed population & Residential density & Industrialization \\
\hline
\end{tabular}

TABle 2: Family annual income of Beijing residents (unit: ten thousand Yuan).

\begin{tabular}{lccccc}
\hline Income & $>100$ & $60-100$ & $40-60$ & $20-40$ & $<20$ \\
\hline Proportion & $8.5 \%$ & $15.8 \%$ & $29.2 \%$ & $29.2 \%$ & $17.3 \%$ \\
\hline
\end{tabular}

2.2.2. MAS Design. In an urban environment, there are numerous factors to take into consideration in urban planning, such as residents, government, and businesses. In this study we focused on the two main influences: residents and government, because the impacts of other agents are relatively small in comparison.

(1) The Design of the Resident Agent Model. Beijing can be divided into five sections based on income statistics. In 2011, we conducted research into income distribution via surveys of 1000 families. We divided the results into five groups, which are shown in Table 2.

To obtain quantitative descriptions of various environmental factors affecting agents' migratory behaviors, we conducted surveys of future residential and environmental demand and behavior from households with different incomes. After statistical analysis, the following five indicators were found to be the most critical factors within the ten set indicators: education, healthcare, green space, service, and transportation. Regarding the proportion of total selected times of each indicator, the weight of agents' annual income hierarchy assignment is shown in Table 3.

(2) Design by Governmental Agent. The governmental agent responsible for planning the urban environment should consider the living environment for residents and urban development from a deep macroscopic aspect, which must include the sustainable development of the environment, economy, and society. The choices of governmental planners impact many aspects of migration and mobility [28]. The governmental planners' choices and the environment are in an interactive relationship. Currently in Beijing, there is a focus on the following of governmental behaviors. These include the formulation and approval of urban comprehensive planning, choosing a population appropriate scale for administering economic development and employment support, the approval of urban residential land development, the improvement of traffic conditions (such as the new construction of new underground rail systems), environmental improvement (such as the increase of urban green space and
TABLE 3: Environmental weight by income levels (unit: ten thousand Yuan).

\begin{tabular}{|c|c|c|c|c|c|}
\hline Income & $>100$ & $60-100$ & $40-60$ & $20-40$ & $<20$ \\
\hline $\begin{array}{l}\text { Educational } \\
\text { Level }\end{array}$ & 13.31 & 14.48 & 14.49 & 16.51 & 14.85 \\
\hline $\begin{array}{l}\text { Sanitary and } \\
\text { medical services }\end{array}$ & 6.66 & 10.82 & 10.14 & 11.92 & 14.55 \\
\hline $\begin{array}{l}\text { Environmental } \\
\text { green space }\end{array}$ & 40.02 & 34.94 & 36.92 & 34.42 & 33.75 \\
\hline $\begin{array}{l}\text { Commercial } \\
\text { services }\end{array}$ & 11.12 & 13.23 & 7.7 & 6.39 & 7.32 \\
\hline $\begin{array}{l}\text { Traffic } \\
\text { convenience }\end{array}$ & 28.9 & 26.54 & 30.34 & 30.76 & 30.01 \\
\hline
\end{tabular}

reconstruction of the old city), and adjustment of residents' income (such as the adjustment of personal income tax exemption). It can be said that the governmental policy and planning are both the control valve and the indicator of residents' migration, mobility, and urban development and expansion [29]. It should be noted that in this model, the governmental agent does not show up in the simulation graph. It is recessive, although its effects can be seen in the model through its impacts on other factors.

\section{Result Analyses}

We used the CA-MAS model on the Swarm simulation platform to simulate the dynamics of the urban population scale and distribution in Beijing, based on the data collected from 2005 to 2011, and analyzed the spatial-temporal characteristics of urban development and changes. First, we conducted the analogue simulation with spontaneous distribution to observe changes in the distribution of the population without imposing any interference from policy and then conducted the simulation with a theoretical guiding policy influencing the distribution. We then observed the differences in population distribution.

3.1. Spontaneous Distribution. According to the set agents' operation rules, without adding any other guiding policies, there is no adjustment for the fitness function. Because the residents mainly consider the affordability of economy location, the problems of housing price will be highlighted. Assuming that the main factors to consider for residents 
TABLE 4: New environmental weight by income levels (unit: ten thousand people).

\begin{tabular}{|c|c|c|c|c|c|}
\hline & Above $100 \%$ & $60-100 \%$ & $40-60 \%$ & $20-40 \%$ & Less than $20 \%$ \\
\hline Educational Level & 13.2 & 14.3 & 14.3 & 16.3 & 14.7 \\
\hline Sanitary and medical services & 6.6 & 10.7 & 10.0 & 11.8 & 14.4 \\
\hline Environmental green space & 39.6 & 34.6 & 36.6 & 34.1 & 33.4 \\
\hline Commercial services & 11.0 & 13.1 & 7.6 & 6.3 & 7.2 \\
\hline Traffic convenience & 28.6 & 26.3 & 30.0 & 30.5 & 29.7 \\
\hline Educational Level & 1 & 1 & 1 & 1 & 1 \\
\hline
\end{tabular}

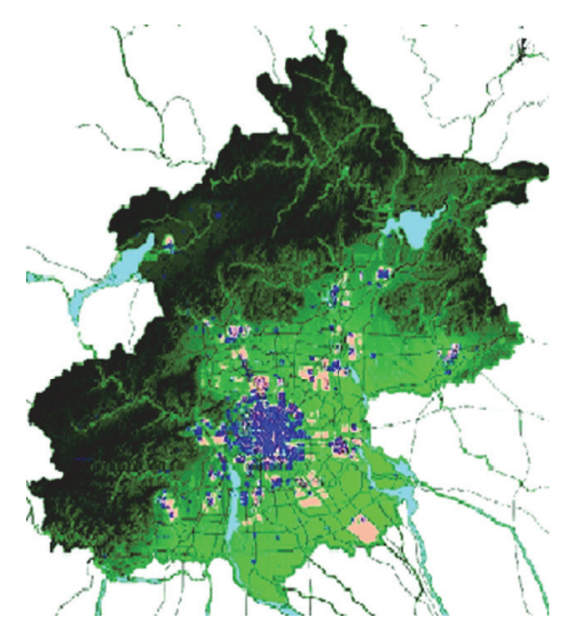

FIGURE 2: Map of Beijing population distribution in 2011.

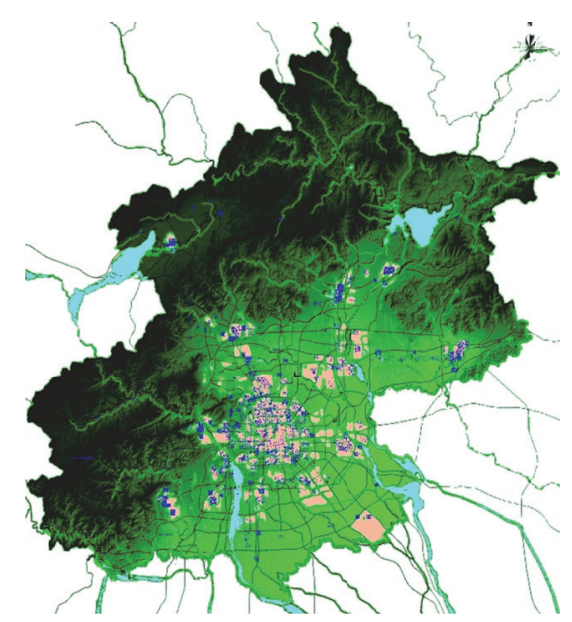

FIgURE 3: Map of Beijing population distribution forecast in 2030.

are income and housing price, the model will highlight the factors "income" and "housing price" in residents' migration, and the focus of residents on other aspects will be less obvious.

The results regarding residents' choice of residences are that Beijing shows a clear hollow, outward diffusing trend (residents are moving away from the center of the city). Figures 2 and 3 show the population density of residential areas. Figure 2 is the spatial distribution of the population in 2011, using population data in the sixth census. This clearly shows the concentration of employment of the population in the city center. Figure 3 is the predicted population distribution in 2030, taking into account the impacts of dominant factors such as residents' income and housing prices and residents' migration. We can see that the hollowing trend (moving away from the city center) has emerged.

Figures 2 and 3 depict population and employment distribution. Under the assumption that the industrial structure of Beijing will change significantly, there is not enough data to make an accurate comparison of day and night ( 24 hour) population migration in the city. According to research conclusions of Cohen Barney, it is a general trend of urban development for employment spatial distribution (especially the service industry) to conglomerate in the city center [30]. However, while employment is concentrated in the center, the residential population is suburbanized [31], which means that the 24 hour mobility of residents will increase rapidly, and urban traffic congestion will become increasingly serious [32]. This is obviously not an expected dynamic for decision makers.

3.2. Guiding Distribution. On the basis of the original model, this simulation adds emphasis to employment indicators and modifies the weights of all indicators to accommodate this. This highlights the impact of employment on urban residents' migration. It gives an extra $1 \%$ weight to the employment indicator and reduces the weights of other indicators in proportion (see Table 4).

Two trends could be identified by observing the simulation results which include the policy effecting residents to choose their residences.

(1) The Population in the Core Area Shows a Significant Downward Trend. Up until 2010 the functional expansion area remained the urban area, with rapid population aggregation. After 2010, however, especially in the predictions for 2030 with the relocation of industry, the population predominantly gathers in the periphery. The new areas developed will become the focus for population aggregation. The population in developments which incorporate ecological conservation also shows a slight increasing trend.

(2) Developing the Population Aggregation of New Areas Which Incorporates Ecological Conservation. With the rise of industrialization, populations at first centralize in the center of towns, then the center of suburbs, which then form a number of new towns. Following that, several small towns with populations of 40,000 to 50,000 develop around these 


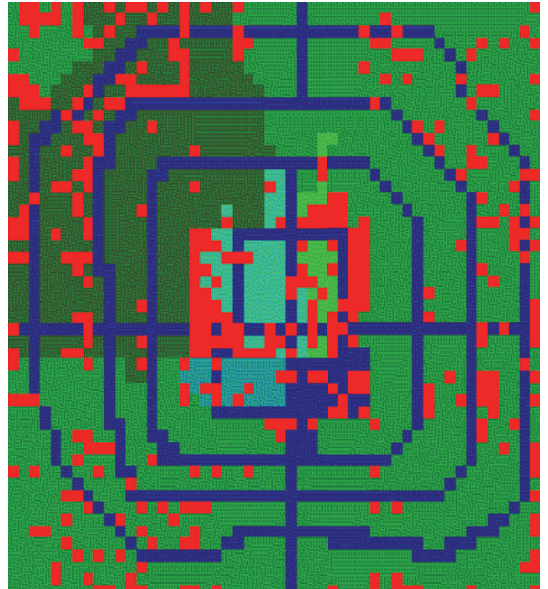

FIGURE 4: Distribution of urban residents in 2010 in Beijing.

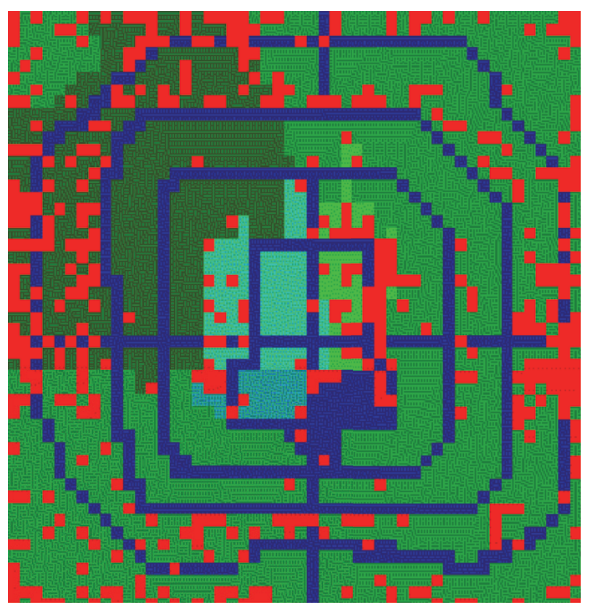

FIgURE 5: Distribution of urban residents in 2030 in Beijing.

new industrial towns. This is most evident in the southeast development area of Beijing. Compared with the previous situation (see Figure 4), these new towns and small towns will form the rudiment of a small city group in 2030 (see Figure 5). Tongzhou, the subsidiary administrative center, is an area set up as a dispersal of Beijing's noncapital functions, as well as an impetus of Beijing's old area reorganization, both led by the national strategy of Integrated Development of Beijing, Tianjin and Hebei Province. The mission of the planning and designing team from all over the world is to build this subsidiary administrative center to be a model of no "urban diseases" area under the standard of "millennium-old city."

3.3. Ways to Optimize the Distribution. To achieve the desired urban development outcomes, development progress needs to be guided down to the level of microcosmic individual behaviors. This can be through environmental improvement and the constraints of policies and regulations [33] and promoting the implementation and evolution of systems designed to promote this. Specifically, this can be achieved in the following ways.

(1) Promote the Homogenization of Public Resources. Public resources like education and health care are important factors for attracting population agglomeration. Regulating this will redistribute the overconcentrated public resources. As well as controlling the urbanization population scale according to production efficiency, this also implements a nondiscriminated public resources allocation policy [28].

(2) Multicenter Group Development Planning. The subcenter approach to peripheral populations is an important way to deal with rapid population agglomeration for China's major cities [34]. The center cities of China should learn from international experience and move beyond the traditional single-center urban planning ideas. The multicenter group development model to development can help China's cities avoid continuing their "pie" expansion.

(3) Promote the Coordinated Development of Employment and Residences. To strengthen the impacts of residents' migration with employment as a driving force, the government should construct an industrial environment which is suitable for coordinating employment and residential areas. Under the current system, the degree of freedom that each has to choice of locations differs. The social service industry and the wholesale industry have a larger range of choice for office locations, the financial industry a smaller range, and the transportation, storage, and postal services have a very narrow range of choice [35]. Urban planning should give industries with smaller selectable ranges of location a priority in zoning. It should also guide residents' choice of residential locations via strengthening the transportation network and designating environmental areas and green spaces, commercial areas, cultural and educational infrastructure, and incentivized mortgage policies in residential areas.

\section{Conclusions and Discussions}

(1) The current distribution of the population in Beijing is inefficient. The speed for population aggregation is slow and the formation of small towns has been stretched out over a long period. This does not meet the strategic direction of China's urbanization development. European urban development experience shows that the multicenter approach to city planning is the only way to achieve sustainable development [36].

(2) Employment opportunities are concentrated in the center of Beijing, but the residential population is suburbanized. This enlarges the urban commuting pressure and makes urban traffic congestion an increasingly serious issue.

(3) The guiding policies to strengthen the residential function of employment locations are effective. The process of interaction between environment and agents accelerates the formation of small town groups. These policies are thus able to effectively reduce the urban commuting pressure and develop urban radiation and diffusion, thus promoting the 
regional economy and the coordinated development of urban and rural areas of Beijing.

(4) The key to enhancing control of population growth and distribution optimization is systematic research and scientific planning. This research and planning should highlight the developmental concepts of "livable city" and "smart city," focus on balancing urban and rural development, promoting the homogenization of public resources and multicenter city development, and coordinate employment and residential areas.

\section{Competing Interests}

The authors declare that there is no conflict of interests regarding the publication of this paper.

\section{Acknowledgments}

This study was funded by National Natural Science Foundation of China (41271187).

\section{References}

[1] S. McCalla, H. L. Minkoff, J. Feldman et al., "The biologic and social consequences of perinatal cocaine use in an innercity population: results of an anonymous cross-sectional study," American Journal of Obstetrics and Gynecology, vol. 164, no. 2, pp. 625-630, 1991.

[2] X. J. Duan, W. Zhang, and F. Tian, "A study on the optimization of population distribution of Yangtze River Delta Region on the background of integration in the region," Resource and Environment in the Yangtze Basin, vol. 21, no. 7, pp. 789-796, 2012 (Chinese).

[3] J. Dijkstra, H. J. Timmermans, and A. Jessurun, "A multi-agent cellular automata system for visualising simulated pedestrian activity," in Theory and Practical Issues on Cellular Automata, pp. 29-36, Springer, London, UK, 2001.

[4] G. C. Sirakoulis, I. Karafyllidis, and A. Thanailakis, "A cellular automaton model for the effects of population movement and vaccination on epidemic propagation," Ecological Modelling, vol. 133, no. 3, pp. 209-223, 2000.

[5] Q. Guan, L. Wang, and K. C. Clarke, "An artificial-neuralnetwork-based, constrained CA model for simulating urban growth," Cartography and Geographic Information Science, vol. 32, no. 4, pp. 369-380, 2005.

[6] K. C. Clarke and L. J. Gaydos, "Loose-coupling a cellular automaton model and GIS: long-term urban growth prediction for San Francisco and Washington/Baltimore," International Journal of Geographical Information Science, vol. 12, no. 7, pp. 699-714, 1998.

[7] M. Alahmadi, P. Atkinson, and D. Martin, "Estimating the spatial distribution of the population of Riyadh, Saudi Arabia using remotely sensed built land cover and height data," Computers, Environment and Urban Systems, vol. 41, pp. 167-176, 2013.

[8] M. K. Belete, R. M. Admas, and G. Balazsi, "Stochastic discretestate simulation of cell population growth in different environments," Bulletin of the American Physical Society, vol. 58, pp. 141152, 2013.
[9] M. Krämer and A. Kehlenbach, "Interactive, GPU-based urban growth simulation for agile urban policy modelling," in Proceedings of the 27th European Conference on Modelling and Simulation (ECMS '13), Ålesund, Norway, May 2013.

[10] O. O. Osunkoya, C. Perrett, C. Fernando, C. Clark, and S. Raghu, "Modeling population growth and site specific control of the invasive Lantana camara L. (Verbenaceae) under differing fire regimes," Population Ecology, vol. 55, no. 2, pp. 291-303, 2013.

[11] N. Malleson, A. Heppenstall, and L. See, "Crime reduction through simulation: an agent-based model of burglary," Computers, Environment and Urban Systems, vol. 34, no. 3, pp. 236250, 2010.

[12] G. C. Sirakoulis, I. Karafyllidis, and A. Thanailakis, "A cellular automaton for the propagation of circular fronts and its applications," Engineering Applications of Artificial Intelligence, vol. 18, no. 6, pp. 731-744, 2005.

[13] N. Hoque, M. E. McCusker, S. H. Murdock, and D. Perez, "The implications of change in population size, distribution, and composition on the number of overweight and obese adults and the direct and indirect cost associated with overweight and obese adults in Texas through 2040," Population Research and Policy Review, vol. 29, no. 2, pp. 173-191, 2010.

[14] H. Y. Lee and B. G. Dodd, "Comparison of exposure controls, item pool characteristics, and population distributions for CAT using the partial credit model," Educational and Psychological Measurement, vol. 72, no. 1, pp. 159-175, 2012.

[15] K. M. Nam and J. M. Reilly, "City size distribution as a function of socioeconomic conditions: an eclectic approach to downscaling global population," Urban Studies, vol. 50, no. 1, pp. 208-225, 2013.

[16] G. Chen, X. Li, and X. Xu, "Spatial agglomeration and evolution of urban population in China," Acta Geographica Sinica, vol. 63, no. 10, pp. 1045-1054, 2008.

[17] P. J. Sun, S. B. Ding, and C. L. Xiu, "Analysis of the coordination of population-economy-space in Beijing," City Planning Review, no. 5, pp. 1-9, 2012 (Chinese).

[18] T. Sun, L. Wang, and G. Li, "Distributions of population and employment and evolution of spatial structures in the Beijing Metropolitan Area," Acta Geographica Sinica, vol. 67, no. 6, pp. 829-840, 2012.

[19] X. D. Gao, Changing of Population Distribution in Large City and Suburbanization Research: A Case Study of Shanghai, Fudan University Press, Shanghai, China, 2003 (Chinese).

[20] H. Y. Xia, "Reasonable capacity of urban population and its measurement research," Population Research, no. 1, pp. 15-21, 2002 (Chinese).

[21] Y. Zhang and X. L. Zhang, "Review and outlook of the research on the urban population carrying capacity," Urban Planning International, no. 1, pp. 11-16, 2013 (Chinese).

[22] F. Wei, Beijing Population Distribution CA/MAS-Based Simulation Model, Harbin University of Science and Technology, Harbin, China, 2007 (Chinese).

[23] Z. W. Peng and J. P. Lu, "Urban population distribution optimization research in Shanghai," Urban Planning Forum, no. 2, pp. 21-26, 2002 (Chinese).

[24] G. Lewis and C. Wilson, "Asset management: what it means for water distribution in large population centers-a case study of the city of Houston large valve program," in Proceedings of the Distribution System Symposium, pp. 1096-1130, 2009.

[25] P. M. Torrens, "Cellular automata and multi-agent systems as planning support tools," in Planning Support Systems in Practice, pp. 205-222, Springer, 2003. 
[26] P. Headicar, "The changing spatial distribution of the population in England: its nature and significance for 'Peak Car," Transport Reviews, vol. 33, no. 3, pp. 310-324, 2013.

[27] E. S. Kurkina and E. D. Kuretova, "General regularities of the distribution of cities by population," Computational Mathematics and Modeling, vol. 23, no. 3, pp. 297-311, 2012.

[28] J. L. Ye, "Discriminating allocation policies of public goods and urban population controlling," Economic Research Journal, no. 11, pp. 27-36, 2006 (Chinese).

[29] J.-C. Dissart, F. Aubert, and D. Lépicier, "Analysing the distribution of population-based employment in France," Regional Studies, vol. 46, no. 9, pp. 1137-1152, 2012.

[30] B. Cohen, "Urban growth in developing countries: a review of current trends and a caution regarding existing forecasts," World Development, vol. 32, no. 1, pp. 23-51, 2004.

[31] B. Meng, "The spatial organization of the separation between jobs and residential locations in Beijing," Acta Geographica Sinica, vol. 64, no. 12, pp. 1457-1466, 2009 (Chinese).

[32] Y. Long, Y. Zhang, and C. Cui, "Identifying commuting pattern of Beijing using bus smart card data," Acta Geographica Sinica, vol. 67, no. 10, pp. 1339-1352, 2012.

[33] X. J. Duan, W. Chen, G. Xu et al., "Optimized population distribution: ecology and economy-oriented appropriate population distribution: a case study of the urban districts of Wuxi City," Resource and Environment in the Yangtze Basin, vol. 17, no. 5, pp. 679-687, 2008 (Chinese).

[34] X. H. Qin, Y. H. Wei, W. Chen et al., "Population expansion and polycentric development of Nanjing city in a period of hypergrowth," Geographical Research, vol. 32, no. 4, pp. 711-719, 2013 (Chinese).

[35] J. Zhang and Y. Chen, "Industrial distribution and clusters of urban office space in Beijing," Acta Geographica Sinica, vol. 66, no. 10, pp. 1299-1308, 2011.

[36] P. Schmitt, "Managing urban change in five European urban agglomerations: key policy documents and institutional frameworks," in Resilience Thinking in Urban Planning, pp. 109-130, Springer, 2013. 


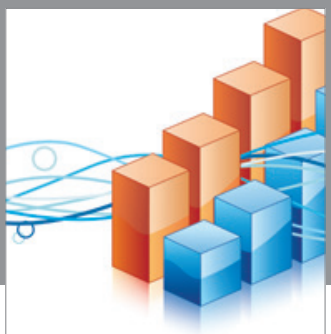

Advances in

Operations Research

vatem alat4

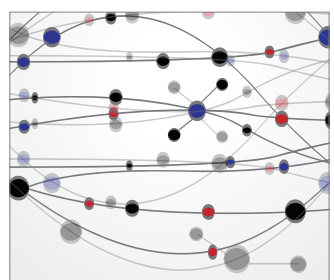

\section{The Scientific} World Journal
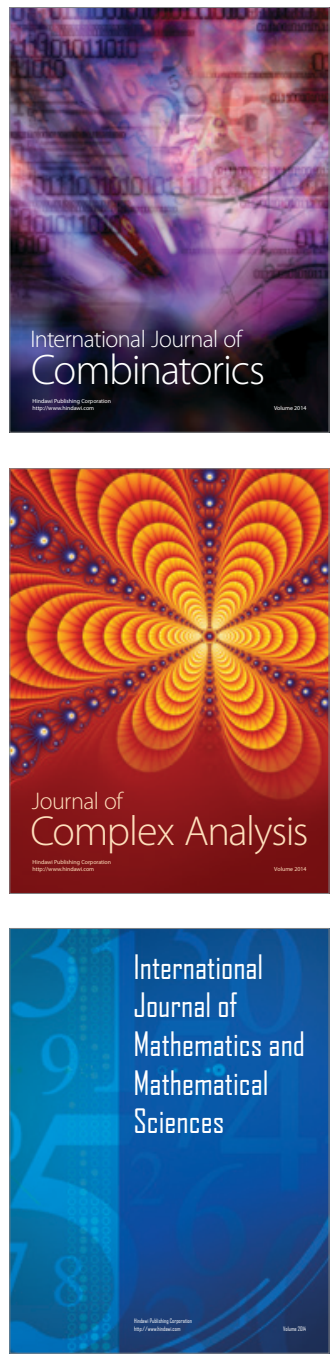
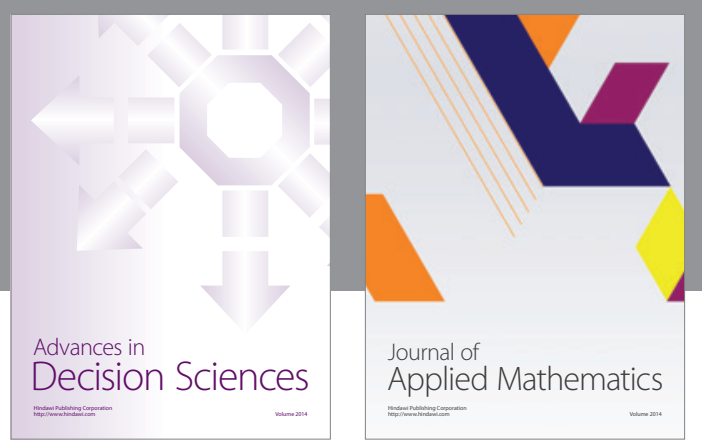

Algebra

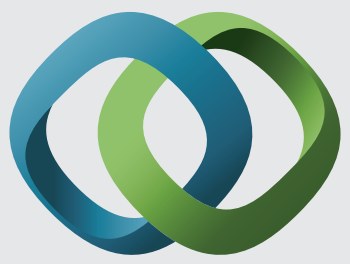

\section{Hindawi}

Submit your manuscripts at

https://www.hindawi.com
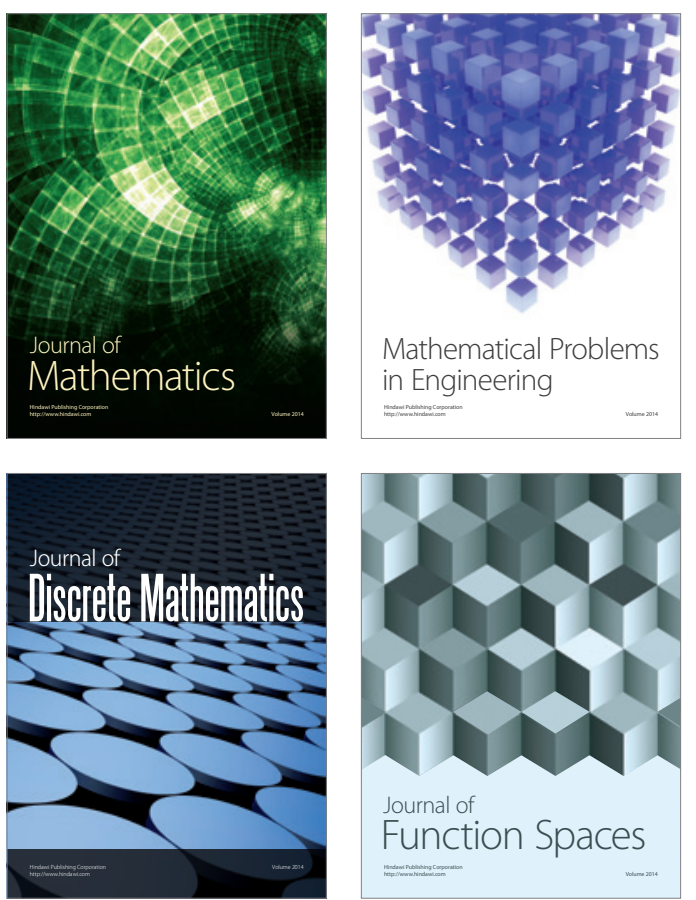

Mathematical Problems in Engineering
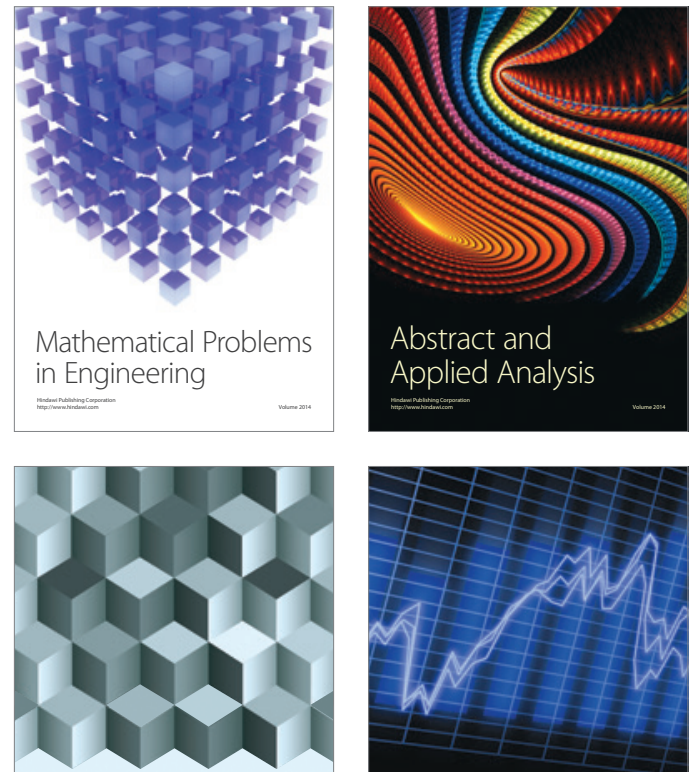

Journal of

Function Spaces

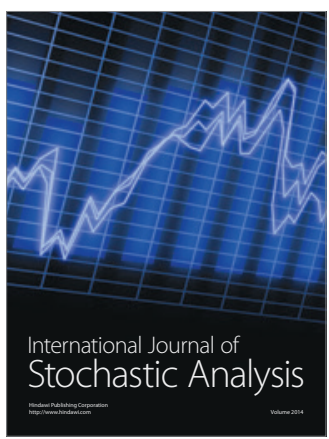

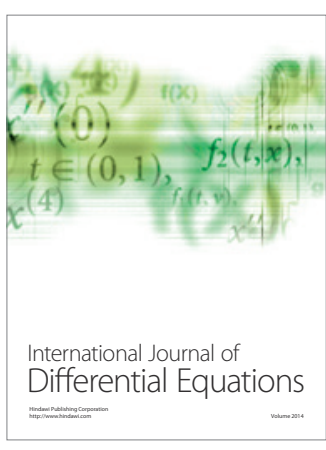
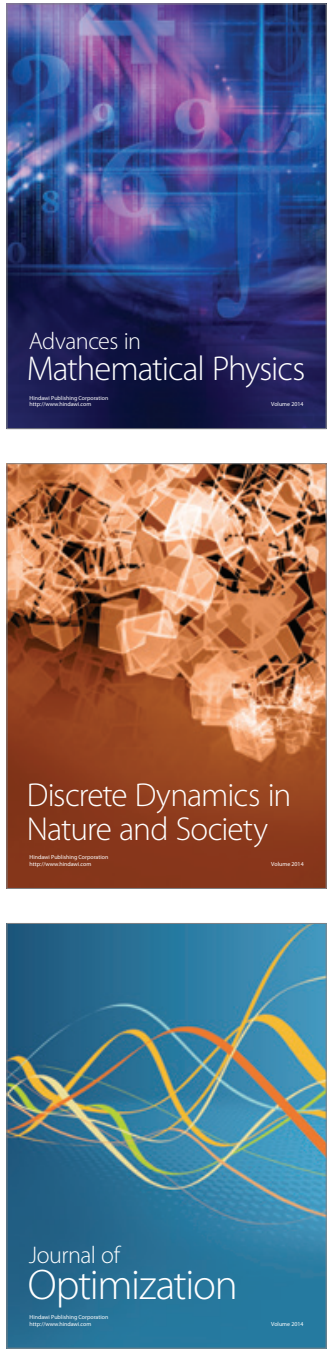